\title{
Estrogenic activity in reused water: comparison of concentration methods
}

\begin{abstract}
Determining the presence of endocrine disrupting substances in waters is a relevant aspect for monitoring environmental health. Given its relevance, it is important to use methods that can make the total concentration of substances with estrogenic activity (eg endocrine disruptors), being faster, and without the use of compounds that pollute the environment. The purpose of the study was to compare the effectiveness of the methods of concentration by lyophilization and by vacuum concentration of substances with estrogenic activity present in reused water, using the commonly used methodology, solid phase extraction. Three methods were compared: solid phase extraction, lyophilization, and vacuum centrifugation. Sample aliquots of reused water received $17 \beta$-estradiol at a final concentration of $2 \mu \mathrm{g} \mathrm{L}^{-1}$ and were concentrated by the three methods. The analysis of estrogenic activity was performed by the in vitro YES (Yeast Estrogen Screen) assay. The results showed that the vacuum centrifugation, solid phase extraction and lyophilization methods had different percentages in the recovery of substances with estrogenic activity, being $45 \%, 40 \%$, and $31 \%$, respectively. The study pointed out that the lyophilization and vacuum centrifugation methods were effective as alternative methods for concentrating samples containing substances with estrogenic activity.
\end{abstract}

Keywords: estrogenic activity, concentration methods, YES assay, reused water, endocrine disrupting chemicals
Volume 5 Issue 3 - 202I

\author{
Natasha Berendonk Handam,' Daniele Maia \\ Bila, ${ }^{2}$ Giselle Gomes Moreira da Silva, ${ }^{2}$ Allan \\ dos Santos Argolo, ${ }^{2}$ Nathalia Rose da Silva \\ Gomes, ${ }^{3}$ Priscila Gonçalves Moura, ${ }^{4}$ Elvira \\ Carvajal, ${ }^{5}$ Adriana Sotero-Martins ${ }^{6}$ \\ 'Doctoral Program in Public Health and Environment, Sergio \\ Arouca National School of Public Health (ENSP), Oswaldo Cruz \\ Foundation (FIOCRUZ), Rio de Janeiro, RJ, Brazil \\ ${ }^{2}$ Laboratory of Sanitary Engineering (LES), Sanitary and \\ Environmental Engineering Department (DESMA), State \\ University of Rio de Janeiro (UERJ), Rio de Janeiro, RJ, Brazil \\ ${ }^{3}$ Specialization in Sanitation Management and Technologies, \\ Sergio Arouca National School of Public Health (ENSP), \\ Oswaldo Cruz Foundation (FIOCRUZ), Rio de Janeiro, RJ, Brazil \\ ${ }^{4}$ Postdoctoral Program in Public Health and Environment, Sergio \\ Arouca National School of Public Health (ENSP), Oswaldo Cruz \\ Foundation (FIOCRUZ), Rio de Janeiro, RJ, Brazil \\ ${ }^{5}$ Biology and Cellular Department (DBC), Roberto Alcantara \\ Gomes Institute of Biology (IBRAG), UERJ, Rio de Janeiro, RJ, \\ Brazil \\ ${ }^{6}$ Sanitation and Environmental Health Department (DSSA), \\ Sergio Arouca National School of Public Health (ENSP), \\ Oswaldo Cruz Fundation (FIOCRUZ), Rio de Janeiro, RJ, Brazil
}

Correspondence: Natasha Berendonk Handam, Doctorate in Public Health and Environment, Sergio Arouca National School of Public Health, Oswaldo Cruz Fundation (ENSP/FIOCRUZ), Rua Leopoldo Bulhões, I 480 - Manguinhos, Rio de Janeiro, RJ, Brazil, Email natashabhandam@gmail.com

Received: March 10, 2021 | Published: June 16, 2021

\section{Introduction}

Water is a finite natural resource, and water scarcity increases with population growth and the demand for fresh water with sanitary quality. A variety of chemical substances are being released into water bodies daily in Brazilian urban and rural areas, such as hormones, chemicals, medicines, cleaning and personal hygiene products, fertilizers, which affect the sanitary quality of the water. ${ }^{1}$ The absorption of chemical substances can interact with human receptors and other organisms present in the environment, through a variety of mechanisms, including endocrine disruption and cytotoxicity. ${ }^{2}$ The presence of endocrine disruptors, such as substances with estrogenic activity, can, even at low concentrations in the order of $\mu \mathrm{g} \mathrm{L-1}$ and ng L-1, cause damage to animal and human health. ${ }^{3,4}$ Therefore, it is important to monitor these substances in water resources in order to prevent harm to human and environmental health. Effluent treatment plants (ETPs) were not designed to eliminate micropollutants, i.e., they do not have mechanisms for removing these substances and, therefore, they remain in the water after the treatment process. ${ }^{5}$ Primary, secondary and, optionally, tertiary treatment processes are commonly used in ETPs. The latter is used to obtain better quality effluent, such as reused water, in which pathogens resistant to previous processes are removed, and then other treatments are carried out to produce reused water. An example of reused water treatment consists of including the sewage treatment by the STP, additional processes such as the application of techniques that use nanofiltration (NF) membranes and reverse osmosis (RO). ${ }^{6,7}{ }^{7}$ However, depending on the origin and treatment of reused water, there are scientific uncertainties about the use of this water, as micropollutants can persist to treatment processes. $^{2}$

Reused water is defined as the reuse of water, which comes from treated effluents. ${ }^{9}$ The reused water can be classified according to Moura et al. ${ }^{10}$ as:

"(i) Local or internal reuse, coming from gray waters from residential reuse (house or building) and reuse of new commercial enterprises or not. Considering that, according to Fiori et al. (2005), gray waters are those coming from washbasins, showers, tanks and washing machines and dishwashers; (ii) External reuse, coming from black waters (raw sewage) from sewage treatment plants and which then pass through reused water treatment plants (STP +RWTP). Considering that, according to GONÇALVES (2009), black waters are effluents from toilets, basically containing feces, urine and toilet paper or from feces and urine separating devices, having in their 
composition large amounts of fecal matter and toilet paper; suspended solids, largely sedimentable; (iii) Industrial reuse, coming from water from the industrial activities of the enterprise itself (direct internal reuse) or from external reuse."

Reused water has been studied as an alternative and sustainable source for society, and has the potential to be used in various activities such as, for example, agriculture, industry, household activities, car washing, urban cleaning, and flowerbed watering. ${ }^{11}$

Among the chemical pollutants that may be present in reused water, substances with estrogenic activity are present. These compounds can interact with estrogen receptors and have an adverse effect on human and animal organisms, causing endocrine disruption. ${ }^{12}$ Endocrine disruptors are defined by EPA ${ }^{13}$ as "an exogenous agent interfering with the synthesis, secretion, transport, binding, action or elimination of natural hormones in the body that are responsible for maintaining homeostasis, reproduction, development and / or behavior". The main substances found in water with high estrogenic activity are the natural hormones estrone and 17 $\beta$-estradiol, and the synthetic hormone $17 \alpha$-ethinylestradiol, which is the main active substance in oral contraceptives; ${ }^{14}$ alkylphenols and alkylphenol ethoxylates. ${ }^{15}$ It is noteworthy that synthetic estrogens have greater estrogenic activity compared to natural hormones. ${ }^{16}$ Other substances also have estrogenic activity, such as those used or produced by industries, such as polychlorinated biphenyls, pesticides, polycyclic aromatic hydrocarbons, phthalates, alkylphenols, and have been found in natural waters and (raw and treated) sewage. ${ }^{12}$

In order to analyze the presence and quantify substances with estrogenic activity in water samples, Routledge and Sumpter ${ }^{17}$ developed an in-vitro analysis method, which is the method used in the study. This technique uses the genetically modified yeast Saccharomyces cerevisiae. The assay allows the identification of chemical substances that are capable of interacting with the human estrogen receptor and elucidating an estrogenic response. The method known as YES (Yeast Estrogen Screen) is widely used due to its effectiveness, reproducibility, and sensitivity.

Before analyzing the estrogenic activity in water, it is necessary to concentrate the substances present in the samples. The method commonly used for concentration is the one that uses a cartridge (with adsorbent matrix), i.e., the solid-phase extraction (SPE) method ${ }^{18,19}$ This technique is efficient, but it is expensive, and uses solvents such as hexane and methanol, that pollute the environment and pose a risk to human health. ${ }^{20,21}$ Although less used than SPE to concentrate these substances, freeze-drying and vacuum centrifugation methods have also been used. These two methods have similar principles, which aim to preserve the chemical composition of the sample, as only water is removed. The lyophilization and vacuum centrifugation methods have advantages, as they allow the realization of the total concentration of estrogenic substances (dissolved and suspended solids) without the need to filter the reused water before concentration. In addition, these techniques do not use chemical solvents during the process, so they are less polluting compared to the SPE method, which uses solvents such as methanol and hexane (FISPQ, 2011). These methods are also faster compared to SPE as they can be performed and completed on the same day they start.

Lyophilization is a process in which a sample is previously frozen and then the amount of solvent (usually water) is reduced, first by sublimation and later by desorption, to valuessuch as to prevent the maintenance of biological activity and chemical reactions; and go through the processes of initial freezing, primary and secondary concentrations. ${ }^{22}$ The lyophilization method is carried out at low temperature, and this is maintained throughout the process, avoiding any chemical alteration of substances sensitive to heat and humidity. ${ }^{23}$ For this reason, a product concentrated by this technique keeps the original chemical composition and other characteristic properties of the sample unchanged. Xavier ${ }^{24}$ performed lyophilization to dehydrate samples containing genistein, which is the soy flavonoid, which has estrogenic activity.

As for the vacuum centrifugation concentration method, it has state-of-the-art vacuum centrifugation technology to remove solvents and concentrate samples, maintaining the integrity of the sample. This technique offers fast and effective concentration and drying of small volume of samples, being generally used to concentrate DNA or RNA. ${ }^{25}$ Vacuum centrifugation references generally involve DNA samples, ${ }^{26} \mathrm{RNA}^{27}$ and proteins. ${ }^{28}$

Given the relevance of determining the presence of endocrine disruptors for environmental health, it is important to use methods that are faster and less polluting for the environment. The research aimed to compare the effectiveness of the methods of concentration by lyophilization and by vacuum concentration of substances with estrogenic activity present in reused water, with the methodology commonly used, the solid phase extraction.

\section{Materials and methods}

The collection of water sample, of the reused water type, from a Reused Water Treatment Plant (RWTP) was carried out in the state of Rio de Janeiro, Brazil, in sterile amber glass. The reused water was produced from the treated sewage (primary and secondary treatment) and then went through three more treatment steps: filtration, ultrafiltration, and reverse osmosis.

In order to compare the methods in terms of their efficacy in the concentration of substances with estrogenic activity and to ensure that the sample contained a known amount of $17 \beta$-estradiol, aliquots of the reused water sample were artificially contaminated with $17-\beta$-estradiol, in the final concentration of $2 \mu \mathrm{g} \mathrm{L} \mathrm{L}^{-1}\left(2,000 \mathrm{ng} \mathrm{L}^{-1}\right)$. Afterwards the aliquots were concentrated by the three methods: Lyophilization, SolidPhase Extraction (SPE), and Vacuum centrifugation. A stock solution of $17-\beta$-estradiol of $54.48 \mu \mathrm{g} \mathrm{L}^{-1}$ in absolute ethanol was used (HPLC type, brand Merk). Aliquots of $250 \mathrm{~mL}$ of sample were used for each concentration method: Lyophilization and SPE. In the concentration by the Vacuum centrifugation method, $10 \mathrm{ml}$ aliquots of the reused water sample were used. The same amounts of aliquot volumes in the sample were also concentrated by the three concentration methods without having been artificially contaminated with the addition of $17-\beta$-estradiol. This allowed to verify the percentage of recovery of each concentration method after the determination of estrogenic activity by the YES (Yeast Estrogen Screen) assay.

\section{Concentration by the solid-phase extraction (SPE) method}

Aliquots of $250 \mathrm{ml}$ of reused water sample were filtered through a $1.2 \mu \mathrm{m}$ glass fiber membrane (Merck), and then through a 0.45 $\mu \mathrm{m}$ cellulose acetate membrane (Merck). Strata-X (Phenomenex ${ }^{\circledR}$ ) $500 \mathrm{mg} / 6 \mathrm{~mL}$ cartridges were used, previously conditioned by washing with: $3 \times 2 \mathrm{~mL}$ of hexane; 1 X $2 \mathrm{~mL}$ of acetone; $3 \times 2$ $\mathrm{mL}$ of methanol (HPLC grade, Tedia ${ }^{\circledR}$ ); and $5 \mathrm{X} 2 \mathrm{~mL}$ of ultrapure water with $\mathrm{pH}$ adjusted to 3 , with $3 \mathrm{M} \mathrm{HCl}$ solution. Subsequently, the sample was percolated in the cartridge with the aid of a vacuum 
pump, in a Manifold system (Agilent VacElut 12). The analytes were eluted after four washes with $4 \mathrm{X} 1 \mathrm{~mL}$ of acetone, which was completely evaporated by a stream of nitrogen. ${ }^{29,30}$ Then the sample was reconstituted with $2 \mathrm{~mL}$ of ethanol and stored at $-20^{\circ} \mathrm{C}$ until the YES assay was performed. Therefore, the content of the sample was concentrated 125 times, since it is at the end in $2 \mathrm{~mL}$.

\section{Concentration by the lyophilization method}

Before using the equipment, the glass parts of the lyophilizer were cleaned with bleach and ethanol. With each new use, these parts were washed with extra 5\% detergent, and rinsed 10 times with deionized water, for total removal of the detergent; then the parts were rinsed with acetone P.A. and rinsed five times with deionized water, followed by rinsing with ethanol P.A. and rinsed with deionized water three times. Volumes of $25 \mathrm{~mL}$ of the sample were transferred and frozen on the lyophilizer flask wall until the total volume of $250 \mathrm{~mL}$ was completed, in order to obtain thin layers superimposed on the glass wall. The sample container was coupled to the lyophilizer at $-100^{\circ} \mathrm{C}$, $220 \mathrm{Vac}$ and $49 \mu \mathrm{Hg}$ for 24 hours. After complete drying, the flask was kept in the $-20^{\circ} \mathrm{C}$ freezer. On the day of the YES assay, the sample was resuspended in a total volume of $1.5 \mathrm{~mL}$ of $99.9 \%$ absolute alcohol (EMSURE® ACS, ISSO, Ph Eur Reag. of the Merk brand), which after an alcohol evaporation step was reduced to $0.75 \mathrm{~mL}$. Therefore, the content of the sample was concentrated 333 times.

\section{Concentration by the method of vacuum centrifugation (speed-vacuum)}

A volume of $0.1 \mathrm{~mL}$ of the reused water sample was transferred to $482.2 \mathrm{~mL}$ microtubes, and then placed in a freezer $-70^{\circ} \mathrm{C}$ for freezing for $5 \mathrm{~min}$. Then, the 48 microtubes with frozen sample were centrifuged in the SpeedVac Concentrator ${ }^{\circledR}$ for 40 minutes, at room temperature, until complete drying. To each of these microtubes, another $0.1 \mathrm{~mL}$ of the same sample was added, and subjected to vacuum centrifugation, as before, until completing $10 \mathrm{~mL}$ of reused water sample. Subsequently, each aliquot of the dry sample in the microtube was resuspended in $0.1 \mathrm{~mL}$ of $99 \%$ absolute ethanol (EMSURE® ACS, ISO, Ph Eur Reag. Merk brand). Then, the volume of each of the 48 microtubes was passed from one microtube to the other until it was in a single microtube. Then, the tubes were washed again with ethanol, passing the sample from one tube to another, taking care to recover the entire sample from the walls of the microtube. During this procedure, the microtubes were kept in an ice bath. The microtube containing the total resuspended volume, approximately 1 $\mathrm{mL}$, was kept in a laminar flow hood for alcohol evaporation until the volume was reduced to $0.2 \mathrm{~mL}$, and then the sample was stored in a freezer $-20^{\circ} \mathrm{C}$. Therefore, the content of the sample was concentrated 50 times.

\section{YES (Yeast Estrogen Screen) in vitro assay}

The presence of substances with estrogenic activity in the reused water was determined through in vitro YES (Yeast Estrogen Screen) assays, according to Routledge and Sumpter ${ }^{17}$, with adaptations described by Dias et $\mathrm{al}^{29}$ In the YES assay, the presence of substances with estrogenic activity triggers the activation the human estrogen receptor (hER) of the contained in the genetically modified yeast Saccharomyces cerevisiae. In this way, a lac- $Z$ gene receptor is expressed, and the enzyme $\beta$-galactosidase is producted, which degrades the chromogenic substrate chlorophenol red$\beta$-Dgalactopyranoside - CPRG (which has a yellow color) into chlorophenol red-CPR (which has a red color). Then, the colorimetric response is quantified by means of a spectrophotometer (absorbance at $575 \mathrm{~nm}){ }^{17}$

For this study, a standard curve was made with $17 \beta$-estradiol as a positive control (E2), from a stock solution in the concentration of $54.48 \mu \mathrm{g} \mathrm{L}^{-1}$ prepared from $17 \beta$ estradiol (> 98\%, Sigma-Aldrich $\left.{ }^{\circledR}\right)$ in ethanol (HPLC grade, Tedia $\left.{ }^{\circledR}\right)$. The negative control (White) was performed with $99 \%$ absolute ethanol (EMSURE® ACS, ISSO, Ph Eur Reag. of brand Merk).

The assay was carried out in 96-well microplates, where the standard E2 solution and the extracts of the sample aliquots concentrated by the freeze-drying, vacuum centrifugation and SPE methods were serially diluted in ethanol. The calibration curve was in the range from 2724 to $1.33 \mathrm{ng} \mathrm{L}^{-1}$. Then, in another microplate, $10 \mu \mathrm{L}$ of each dilution was transferred (duplicate) and allowed to evaporate until dry. Then, $200 \mu \mathrm{L}$ of culture medium containing yeast and CPRG were added to the wells. After that, the plates were sealed with tape and shaken vigorously for 2 minutes. Then, the plates were incubated for $72 \mathrm{~h}$ at $30^{\circ} \mathrm{C}$, and the absorbances were read at $540 \mathrm{~nm}$ (for colors) and $620 \mathrm{~nm}$ (for turbidity) using the spectrophotometer (Softmax brand, model SpectraMax M3).

Calculation of the corrected absorbance of the data from each well of the assay microplate was performed, using the absorbance values obtained at the two wavelengths for each concentration of the curve, according to the calculation presented in Argolo et al. ${ }^{18}$ As a control of the YES assay, the growth inhibition of the yeast Saccharomyces cerevisiae was quantified due to the toxicity of the samples, according to Frische et al..$^{32}$ Sigmoidal curves were obtained using a symmetric logistic function using the Origin 6.0 program (Microsoft, USA). The estrogenic activity in each well containing sample extract was then calculated as estradiol equivalents (EQ-E2) in $\mathrm{ng} \mathrm{L}^{-1}$, by interpolation with the E2 dose-response curve. These values were multiplied by the concentration factor of each tested method, resulting in the final concentrations for the reused water sample aliquots as E-EQ (ng L1 range). E2 standard curves with median effect concentration (EC50) of 56.58 and $44.36 \mathrm{ng} \mathrm{L}^{-1}$ were used for each assay, respectively. The assay had the limits of detection (LOD) and quantification (LOQ) equal to $12 \pm 2 \mathrm{ng} \mathrm{L}^{-1}$ and $35 \pm 11 \mathrm{ng} \mathrm{L}^{-1}$.

\section{Results and discussion}

The estrogenic activity was determined, referring to the $17 \beta$-estradiol (E2) substance included in the sample of reused water processed through the three concentration processes tested: solidphase extraction, lyophilization and vacuum concentration.

The concentration method by vacuum centrifugation was the one that least interfered with losses of substances, with greater recovery. Of the 2,000 $\mathrm{ng} \mathrm{L}^{-1}$ of $\mathrm{E} 2$ inserted in the doped sample, estradiol equivalent (EQ-E2) of $895 \mathrm{ng} \mathrm{L}^{-1}\left( \pm 5 \mathrm{ng} \mathrm{L}^{-1}\right)$ was detected, corresponding to $45 \%$ of what was initially added; the solid phase extraction method recovered $790 \mathrm{ng} \mathrm{L}^{-1}\left( \pm 23 \mathrm{ng} \mathrm{L}^{-1}\right), 40 \%$ estradiol equivalent (EQ-E2); followed by the lyophilization method that recovered $610 \mathrm{ng} \mathrm{L}^{-1}\left( \pm 6 \mathrm{ng} \mathrm{L}^{-1}\right) 31 \%$ of the estradiol equivalent concentration (EQ-E2) initially added to the sample (Table 1). The samples that were not doped showed results below the detection limit, using the mathematical formula according to Routledge and Sumpter ${ }^{17}$, it is suggested that there are no substances with estrogenic activity in the reused water sample studied. The sample in this study did not show cytotoxicity, which would inhibit the growth of the yeast Saccharomyces cerevisiae in the YES assay. 
Table I Percentage that each concentration method was able to recover from estradiol equivalent (EQ-E2), which was inserted in the aliquots of the doped samples (final concentration $2,000 \mathrm{ng} \mathrm{L}^{-1}$ of E2), and standard deviation (SD) of the results

\begin{tabular}{llll}
\hline Methods & Recovery (\%) & (EQ-E2) ng L-1 & SD \\
\hline $\begin{array}{l}\text { Vacuum } \\
\text { centrifugation }\end{array}$ & 45 & 895 & 5 \\
$\begin{array}{l}\text { Solid-phase } \\
\text { extraction }\end{array}$ & 40 & 790 & 23 \\
\begin{tabular}{l} 
Lyophilization \\
\hline
\end{tabular} & 31 & 610 & 6 \\
\hline
\end{tabular}

The vacuum centrifugation and lyophilization methods can be used as alternative techniques for the concentration of $17 \beta$-estradiol in a sample of reused water. It is noteworthy that in the sample's doped aliquots the concentration was above the concentration of
2,000 $\mathrm{ng} \mathrm{L}^{-1}$ of E2 in the standard curve of the YES assay, indicating the presence of substances with estrogenic activity in the sample itself Figures $1,2, \& 3$. However, the results obtained by means of the calculation proposed by Roudledge and Sumpter ${ }^{17}$ showed that the non-doped samples and concentrated by the three methods, the estrogenic activity was below the minimum level of detection. This result indicated that the treatment of the sample of reused water analyzed was effective. This water was produced by sewage treatment (primary and secondary treatment) followed by procedures performed with membranes, filtration, ultrafiltration and reverse osmosis. The data obtained demonstrated that this process of obtaining reused water was effective in removing substances with estrogenic activity. In fact, there are other reports that corroborate with the statement that this type of treatment is effective for the elimination of inorganic (such as nitrate, arsenic and fluorine) and organic micropollutants (such as pesticides, estrogens, among others). ${ }^{6,7}$
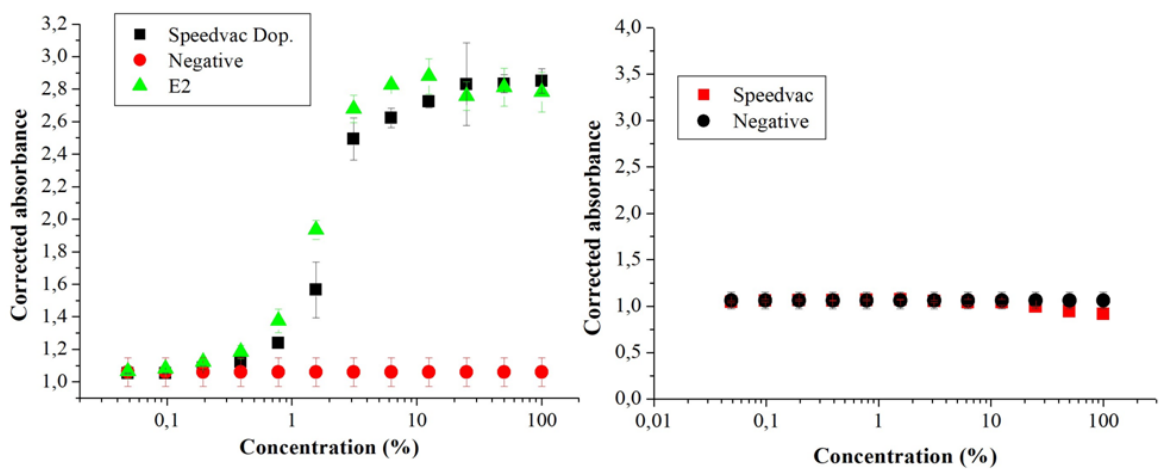

Figure I (A) Dose-response curves in the YES test of a sample of reused water artificially contaminated by I7ß-estradiol (E2) (Speedvac Dop.), of the positive (E2) and negative control (White); (B) dose-response curves of a reused water sample without having been artificially contaminated, concentrated by the vacuum centrifugation (Speedvac) method, and the negative control (White). Source: the author itself.
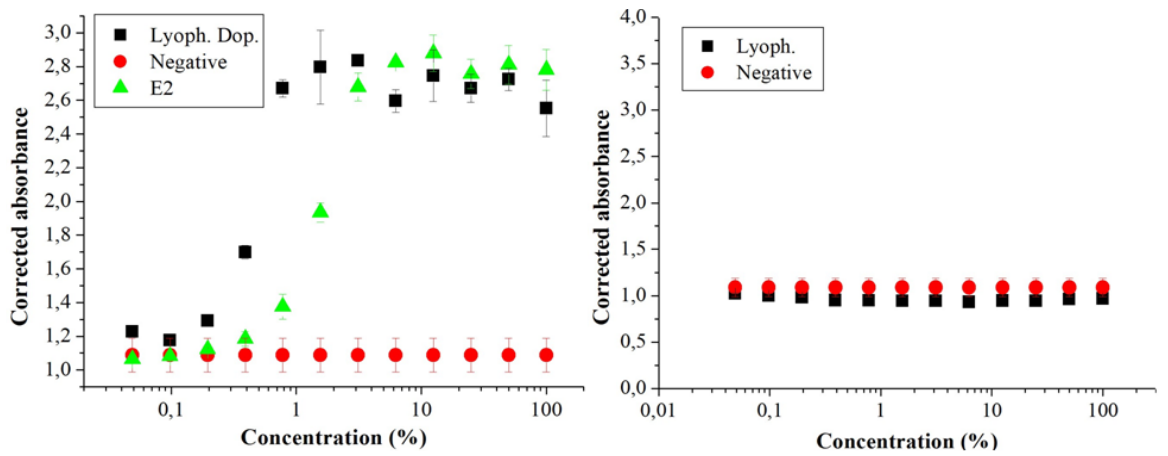

Figure 2 (A) Dose-response curves in the YES test of a sample of reused water artificially contaminated by I7ß-estradiol (E2) (Lyoph. Dop.), of the positive (E2) and negative control (White); (B) dose-response curves of a reused water sample without having been artificially contaminated, concentrated by the lyophilization (Lyoph.) method, and the negative control (White). Source: the author itself.
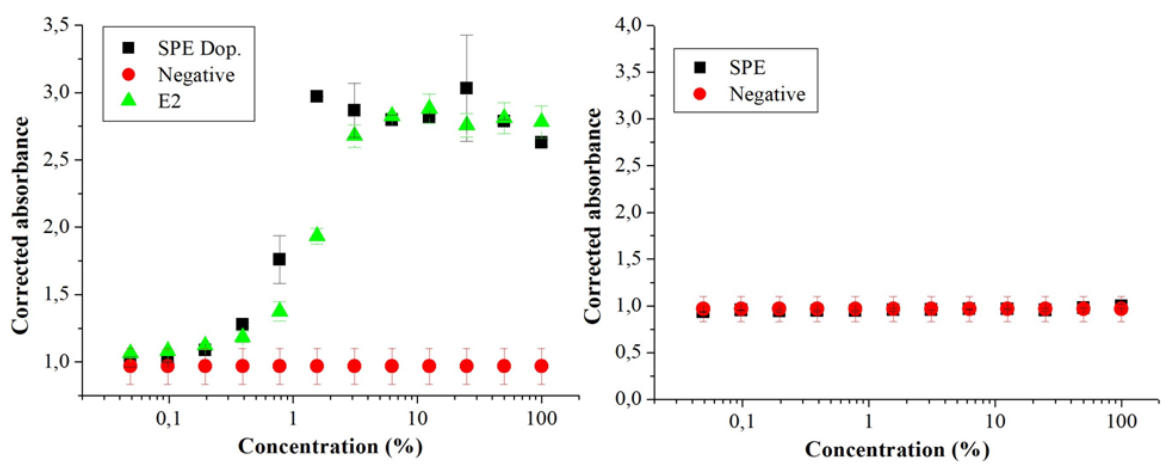

Figure 3 (A) Dose-response curves in the YES assay of a sample of reused water artificially contaminated by I7ß-estradiol (E2) (SPE Dop), of the positive (E2) and negative control (White); (B) sample of reused water without having been artificially contaminated, concentrated by the Solid Phase Extraction method (SPE), and the negative control (White). Source: the author itself. 
The recovery percentages found for each method can be considered low. Vacuum centrifugation was the technique in which the highest percentage $(45 \%)$ of recovery was observed, a value close to the solid phase extraction method ( $40 \%)$. However, according to Gatidou et al..$^{33}$ the solid phase extraction method can have percentages of recovery of the analytes that vary from 10 to $90 \%$. Solid-phase extraction is a consolidated methodology, and there are studies that have recorded a higher percentage of recovery than that verified in this paper, reaching up to $100 \%$ recovery. ${ }^{33,34}$

There were losses of $17 \beta$-estradiol concentration equivalents during the sample concentration processes. The reason for losses due to lyophilization, SPE, and vacuum centrifugation can be associated with the transfer of the sample to the different vials, and it is not possible to fully recover the sample volume. The loss obtained with the vacuum centrifugation method can be associated with the fact that the procedure is performed in open microtubes, and during the centrifugation the sample aliquots are heated, which may favor the loss of part of the substances by volatilization. ${ }^{35}$

It is worth mentioning, however, that the freeze-drying and vacuum centrifugation methods allow the total concentration of estrogenic substances (dissolved and suspended solids) to be made, and it is not necessary to filter the water before the concentration. Estrogenic substances have been found in greater quantity in the dissolved aqueous phase ${ }^{36}$ however, the adsorption to the solid phase of the matrix cannot be neglected, as estrogenic substances have high lipophilicity and low volatility. ${ }^{37,38,39}$ National and international studies have demonstrated through effective results the importance of analyzing dissolved solids and suspended solids in aqueous environmental matrices for the quantification of total estrogenic activity ${ }^{38,39,40}$ In another study, the relevance of quantifying the total estrogenic activity of aqueous environmental matrices considering the solid fractions was also shown. ${ }^{18}$

The vacuum centrifugation and lyophilization methods used to concentrate substances with estrogenic activity are methods that do not require the use of chemical solvents for the concentration of samples. In this sense, they are less polluting compared to the SPE method, in which solvents such as methanol, hexane, are used. According to the FISPQ document, ${ }^{41}$ the solvents used for the solid-phase extraction are flammable and toxic products, being polluting to the environment and can cause damage to human and animal health. Methanol, for example, can cause blindness or even death by ingesting 30 to 100 $\mathrm{mL}$ of it. ${ }^{41}$ In addition, they need handling care, in which contact with skin, eyes and clothing should be avoided, and good hygiene practices should be followed.

It should also be noted that the alternative methods studied are fast techniques for concentrating substances with estrogenic activity in reused water compared to the solid-phase extraction method, as they can be carried out and completed on the same day the sample analysis begins.

\section{Conclusion}

The results showed that the vacuum centrifugation, solid phase extraction and lyophilization methods had different percentages in the recovery of substances with estrogenic activity, being $45 \%, 40 \%$, and $31 \%$, respectively.

The study showed that the lyophilization and vacuum centrifugation methods were effective as alternative techniques for the concentration of substances with estrogenic activity in the reused water, allowing later their measurement by the YES assay. With this, the possibility of using alternative concentration methods, such as lyophilization and vacuum centrifugation in laboratories having a lyophilizer and a vacuum concentrator, will make the analysis of these types of substances more affordable. In addition, these techniques perform the total concentration of substances with estrogenic activity in the water, which ensures a better and more accurate assessment of the sanitary quality of the water in relation to chemical pollutants. Using vacuum centrifugation and lyophilization methods, it is possible to start the Yes assay to determine estrogenic activity on the same day. Therefore, the analysis result becomes faster. These techniques also do not require the use of chemical products for concentration, which reduces the disposal of chemical compounds in the environment, favoring sustainability. It is noteworthy that the sample of reused water collected for the study did not present substances with estrogenic activity. The analysis of the estrogenic activity determination assay showed that the sample concentration performed by vacuum centrifugation was the one that managed to recover the greatest amount of the inserted estradiol, however it had a recovery percentage similar to the solidphase extraction method.

\section{Acknowledgments}

Acknowledgments to the Research Support Foundation of the State of Rio de Janeiro - FAPERJ; and the Sergio Arouca National School of Public Health - ENSP, Oswaldo Cruz Foundation - FIOCRUZ; Post Graduate Support Program from the Coordination for Improvement of Higher Education Personnel - PROAP/CAPES; Sanitary Engineering Laboratory (LES), and Department of Biology and Cellular (DBC), State University of Rio de Janeiro (UERJ).

\section{Conflicts of interest}

The authors have no conflicts of interest to declare.

\section{References}

1. Aquino SF, Brandt EMF, Chernicharo CAL. Remoção de fármacos e desreguladores endócrinos em estações de tratamento de esgoto: revisão da literatura. Revista de Engenharia Sanitária e Ambiental. 2013;18(3):187-204.

2. Scarpa F, Megersa DD, Karimi S. Reuse of Water: Methods to diminish non-biodegradable organic compounds. WWT Project Wort, KTH. 2011.

3. GORE AC, David Crews, Loretta L Doan, et al. Introduction to endocrine disrupting chemicals (EDCs) a guide for public interest organizations and policy-makers. The Endocrine Society and IPEN, 2014. p. 76.

4. Bila DM, Dezotti M. Desreguladores endócrinos no meio ambiente: efeitos e consequências. Química Nova. 2007;30(3):651-666.

5. Luo Y, Guo W, Ngo HH, et al. A review on the occurrence of micropollutants in the aquatic environment and their fate and removal during wastewater treatment. Science of the Total Environment. 2014;473:619-641.

6. Mancuso PCS, Santos HF. Reúso de Água. $1^{\text {th }}$ ed. São Paulo: Manole Editora; 2013

7. Bolong N, Ismail AF, Salim MR, et al. A review of the effects of emerging contaminants in wastewater and options for their removal. Desalination. 2009;239:229-246.

8. Oenning Júnior A, Pawlosky U. Avaliação de tecnologias avançadas para o reúso de água em indústria metal-mecânica. Revista de Engenharia Sanitária e Ambiental. 2007;12(3):305-316.

9. Morais MA, Miguel FN, Gleydson FS, et al. Contaminação microbiológica no perfil do solo por águas residuárias. Holos. 2016;3:76. 
10. Moura PG, Aranha FN, Handam NB, et al. Água de reúso: uma alternativa sustentável para o Brasil. Eng Sanit Ambient. dezembro de 2020;25(6):791-808.

11. ABNT - ASSOCIAÇÃO BRASILEIRA DE NORMAS TÉCNICAS. NBR 13.969 de 30 de outubro de 1997. Unidades de tratamento complementar e disposição final dos efluentes líquidos. Rio de Janeiro, out. 1997. p. 60.

12. Ghiselli G, Jardim WF. Interferentes endócrinos no ambiente. Química Nova. 2007;30(3):695-706.

13. EPA - US. Environmental Protection Agency. Special report on environmental endocrine disruption: an effects assessment and analysis. Prepared for the Risk Assessment Forum U.S. Environmental Protection Agency Washington, D.C., 1997.

14. Pessoa GP, Santos AB, Souza NC, et al. Desenvolvimento de metodologia para avaliar remoção de estrogênios em estações de tratamento de esgotos. Química Nova. 2012;35(5):968-973.

15. Teske SS, Arnold RG. Removal of natural and xeno-estrogens during conventional wastewater treatment. Reviews in Environmental Science and Biotechnology. 2008;7(2):107-124.

16. Svenson B, Ann-Sofie A, Mats EK. Removal of Estrogenicity in Swedish Municipal Sewage Treatment Plants. Water Res. 2003;37:4433-4443.

17. Routledge EJ, Sumpter JP. Estrogenic Activity of Surfactants and Some of their Degradation Products Assessed Using a Recombinant Yeast Screen. Environmental Toxicology and Chemistry. 1996;15(3):241-248.

18. Argolo ADS, Gomes G, Bila DM. Insights into total estrogenic activity in a sewage-impacted urban stream assessed via ER transcriptional activation assay: Distribution between particulate and dissolved phases. Ecotoxicology and Environmental Safety. 2021; 208: 111574.

19. Amparo MR. Desenvolvimento e validação de métodos SPE-LC-MS e MEPS-LC-MS para quantificação de fluoroquinolonas em matrizes aquosas. PhD Thesis, Universidade de São Paulo, São Paulo, Brazil. 2013.

20. Assis CS, Jesus LDF, Miranda AC, et al. Uso do metanol e risco de exposição dos trabalhadores de uma usina de biodiesel. Revista Brasileira de Medicina do Trabalho. 2017;15(1):29-41.

21. Freitas NBB, Arcuri ASA. Riscos devido à substâncias químicas. Cadernos de Saúde no Trabalho. Instituto Nacional de Saúde no Trabalho: 2000 .

22. Marques LG. Liofilização de frutas tropicais. PhD Thesis, Universidade Federal de São Carlos, São Carlos. 2008. p. 293.

23. Bartolomeu AM. La liofilización:?' ciencia o arte? Saber y Hacer. 2014;1(1):93-102.

24. Xavier CR. Associação da isoflavona genisteina com beta-ciclodextrina : avaliação da penetração cutânea. $\mathrm{PhD}$ Thesis, Universidade Federal do Rio Grande do Sul, Programa de Pós-Graduação em Ciências Farmacêuticas. 2006.

25. Concentradores Thermo Scientific Savant SpeedVac e Kits SpeedVac. Thermo Scientific. 2011.

26. Bonato ALV, Muniz JB, Maciel JLN, et al. Otimização do método de extração de DNA de Magnaporthe oryzae de trigo. Embrapa Trigo. Comunicado técnico online. Passo Fundo, RS, Brazil. 2014;343.
27. Rodrigues Junior CF. Estudo das bases moleculares envolvidas no efeito lipolítico do hormônio tireoidiano no tecido adiposo branco. $\mathrm{PhD}$ Thesis, Universidade de São Paulo, SP, Brazil. 2011.

28. Andrade SM, Silva M, Silva FSQ. Análise de interferon humano recombinante presente em formulações farmacêuticas. Vigil. sanit. Debate. 2017;5(3):66-75.

29. Dias ACV, Gomes FW, Bila DM, et al. Analysis of estrogenic activity in environmental waters in Rio de Janeiro state (Brazil) using the yeast estrogen screen. Ecotoxicology and Environmental Safety. 2015;120:4147.

30. Cordeiro D. Uso de bioindicador de efeito endócrino e validação do método para determinação de hormônios na água da Represa Municipal de São José do Rio Preto. PhD Thesis, Instituto de Química de São Carlos, Universidade de São Paulo, São Paulo, Brazil. 2009.

31. Bila DM. Degradação e Remoção da Atividade Estrogênica do Desregulador Endócrino 17ß-estradiol pelo Processo de Ozonização. $\mathrm{PhD}$ Thesis in Ciências em Engenharia Química. Universidade Federal do Rio de Janeiro. Rio de Janeiro, 2005.

32. Frische T, Faust M, Meyer W, et al. Toxic masking and synergistic modulation of the estrogenic activity of chemical mixtures in yeast estrogen screen (YES). Enviromental Science and Pollution Research. 2009;16(5):593-603.

33. Gatidou GN, Thomaidis S, Stasinakis AS, et al. Simultaneous determination of the endocrine disrupting compounds nonylphenol, nonylphenol ethoxylates, triclosan and bisphenol A in wastewater and sewage sludge by gas chromatography-mass spectrometry. Journal of Chromatography. 2007;1138(1):32-41.

34. Fernandes AN, Giovanela M, Almeida CAP, et al. Remoção dos hormônios $17 \beta$-estradiol e $17 \alpha$-etinilestradiol de soluções aquosas empregando turfa decomposta como material adsorvente. Química Nova. 2011;34(9):15261533 .

35. Sousa RA, Campos NS, Orlando R. Preparação de amostras para análise elementar. Universidade federeal de juiz de fora. Juiz de Fora. 2015.

36. Williams RJ, Jurgens MD, Johnson AC. Initial predictions of the concentrations and distribution of $17 \beta$-oestradiol, oestrone and ethinyl oestradiol in 3 English rivers. Water Research. 1999;33(7):1663-1671.

37. Birkett JW, Lester JN. Endocrine Disrupters in Wastewater and Sludge Treatment Process. $1^{\text {th }}$ ed. Lewis Publishers; 2003.

38. Dagnino S, Gomez E, Picot B, et al. Estrogenic and AhR activities in dissolved phase and suspended solids from wastewater treatment plants. Science of the Total Environment. 2010;408:2608-2615.

39. Yarahmadi H, Duy SV, Hachad M, et al. Seasonal variations of steroid hormones released by wastewater treatment plants to river water and sediments: Distribution between particulate and dissolved phases. Science of the Total Environment. 2018;635:144-155.

40. Bila DM, Argolo AS, Baptista CL. Atividade estrogênica em matriz ambiental: contribuição dos sólidos suspensos totais. $30^{\circ}$ Congresso Brasileiro de Engenharia Sanitária e Ambiental- ABES. Associação Brasileira de Engenharia Sanitária e Ambiental. RN, Brazil, 2019. p. 7.

41. FISPQ - Ficha de informações de segurança de produto químico. METANOL 2822-P Rev. 16 25/04/2011. Access in: December 9, 2019. 